\title{
ISOLATION AND CHARECTERIZATION OF TAMARIND SEED POLYSACCHARIDES-A NATURAL RELEASE RETARDANT
}

\author{
TRIDEEP SAIKIA, JONAB ALI, BISWAJIT DAS \\ Girijananda Chowdhury Institute of Pharmaceutical Science, Azara, Guwahati, Assam 781017 \\ Email: tsaikia53@gmail.com
}

Received: 28 Jan 2017, Revised and Accepted: 20 Apr 2017

\begin{abstract}
Objective: The main objective was to isolate and characterise a naturally obtain polysaccharides which have the property to formulate sustain release product.
\end{abstract}

Methods: Tamarind Seed Polysaccharides (TSP) was isolated from seed of Tamarindus indica by crushed the seed into powder and boiled with water at $45^{\circ} \mathrm{C}$ to extract the polysaccharides. After boiling for $12 \mathrm{~h}$ the supernatant liquids were collected and stored in cool place. After the liquids become cooled acetone was added and freeze at $-40{ }^{\circ} \mathrm{C}$. Freeze materials then lyophilized to extract out the Tamarind seed polysaccharides. After that polysaccharide was evaluated for organoleptic, micromeritic and other characterization parameter along with microbial contamination

Results: Yield of polysaccharides was found to be $16.85 \%$. As per the micromeritic property flow of polysaccharides, tapped and bulk density was found in acceptable range. Microbial studies confirmed that TSP doesn't support microbial growth.

Conclusion: The polysaccharides were isolated, extracted and characterized. The characterization was carried out for different physiochemical properties and powder properties.

Keywords: Tamarind seed polysaccharides (TSP), Freeze drying, Differential Scanning Calorimetry (DSC), Acute Toxicity.

(C) 2017 The Authors. Published by Innovare Academic Sciences Pvt Ltd. This is an open access article under the CC BY license (http://creativecommons.org/licenses/by/4.0/) DOI: http://dx.doi.org/10.22159/ijcpr.2017v9i4.20972

\section{INTRODUCTION}

Plants have been used as medicines from the ancient times. Throughout the world medicinal plants are widely and successfully used. A plant with active medicinal constituents is used to treat diseases in the traditional systems like Ayurveda, Siddha and Unani. In Asia, the uses of medicinal plants are well established and are well documented. The plants those are recognized internationally mostly come from this region. Plants, plant parts and plant products those are used for the preparation of medicines serve us to uplift the economic status of the country and they are the natural wealth of a country. Medicinal plants have got significant role in saving the lives of rural area people. In India, 45,000 plant species have been identified and out of which 15-20 thousand plants are found to have good medicinal value. Study says about 6000 traditional plants are used in Indian traditional and herbal medicines. 1 Plant derived polysaccharides have evoked tremendous interest due to their diverse pharmaceutical applications such as diluent, binder, disintegrate in tablet formulation, thickeners in oral liquids, protective colloids in suspensions, gelling agents in gels and bases in suppository.2 Polymers are considered ideal for formulating immediate and sustained release preparations due to their high stability, safety, non-toxic, hydrophilic and gel gorming nature [1].

Tamarindus indicia $L$., belongs to the Dicotyledonous family Leguminosae Sub Family Caesalpiniaceae, which is the third largest family of flowering plants with a total of 727 genera and 19, 327 species. Over all $50 \%$ of the population in India is being treated with traditional medicines by almost 50,000 traditional local herbal practitioners and hakims. Tamarindus indica fruit pulp is used for the preparation of beverages in different regions. In India, legumes constitute an important food stuff and are an economic source of protein in the diets of economically weaker sections of population. Some of the wild nuts and seeds used as food in several parts of the world have considerable promise as protein source. Large segments of human population and animals in developing countries suffer from protein malnutrition. They are playing an important role in human nutrition mainly in developing countries. Tamarindus indica contain high levels of crude protein. Tamarindus indica also contains a high level of protein with many essential amino acids which help to build strong and efficient muscles. T. indicais also high in carbohydrate, which provides energy, rich in the minerals, potassium, phosphorus, calcium and magnesium $T$. indica can also provide smaller amounts of iron and vitamin A. T. indica is an important food resource for the Thai population The flower and leaf are eaten as vegetables. T. indica is a plant widely used in traditional medicine in Africa for the treatment of many diseases such as fever, dysentery, jaundice, gonococci and gastrointestinal disorders. Pharmacological investigations on T. indica extracts reported them to have antibacterial, antifungal, hypoglycaemic, cholesterolemic, cytotoxic, anti-inflammatory, gastrointestinal, hypolipomic and antioxidant activities. The phytochemical examination of the methanolic extract of the leaves of T. indica afforded two triterpenes i.e., lupanone and lupeol. Both compounds (metabolites) have been isolated for the first time from $T$. indica. During the present study, fatty acids composition of medicinal plant $\mathrm{T}$. indicia from the different areas of Sindh, Pakistan was evaluated to analyze the saturated and unsaturated fatty acids composition. Analysis was carried out for elements viz., $\mathrm{As}, \mathrm{Ca}, \mathrm{Cd}, \mathrm{Cu}$, $\mathrm{Fe}, \mathrm{K}, \mathrm{Mg}, \mathrm{Mn} \mathrm{Na} \mathrm{P,} \mathrm{Pb}$ and Zinc and total protein [2].

\section{MATERIALS AND METHODS}

\section{Materials}

Tamarind Seed Polysaccharides (TSP) was obtained from forest of Assam, District-Darrang. USP I tapper of a USP tap density tester (Electro lab, model ETD-1020), vortex mixer (Labline Equipment, India), Bench centrifuge (Remi, India), Brookfield viscometer (LVDVE) (Brookfield Engineering Labs, Stoughton-USA), Perkin Elmer 2400 Semis II CHN analyser, differential scanning calorimeter (JADE DSC, Perkin Elmer, and USA), Siemens D5000 X-ray diffractometer (Siemens, Munich, Germany), IR spectrometer (Bruker Alpha FTIR). All other chemicals and solvents used were of analytical grade.

\section{Methodology}

Extraction, purification and characterization of polysaccharides extraction

Seeds of Tamarindus indica was collected and dried in sunlight. After that seeds were crushed into powder and boiled with water at $45^{\circ} \mathrm{C}$ 
to extract the polysaccharides. After boiling for $12 \mathrm{~h}$ the supernatant liquids were collected and stored in cool place. After the liquids become cooled acetone was added and freeze at-40 ${ }^{\circ} \mathrm{C}$. Freeze materials then lyophilized to extract out the Tamarind seed polysaccharides [3].

\section{Characterization of polysaccharides}

\section{Phytochemical examination}

Preliminary tests were performed to confirm the presence of polysaccharide by ruthenium red test and Molisch's test [4].

\section{Organoleptic properties}

Properties like colour, odour, taste, shape, touch and texture were determined [4].

\section{Composition of polysaccharides}

Considering glucose as standard the total sugar content was estimated by the phenol-sulfuric acid analysis. Tests like Molisch tests, Fehling's test and iodine test was performed to determine the total carbohydrate content. UV-visible spectra and Barfoed test were undergone to determine the protein presence [4].

\section{Micromeritic properties of polysaccharides}

Isolated TSP powder was evaluated for bulk density, tap density, angle of repose, Hausner's ratio and Carr's index [5]

\section{Angle of repose}

The polysaccharide (TSP) powder (10 g) was accurately weighed and carefully introduced into a funnel clamped to a stand with its tip $10 \mathrm{~cm}$ from a plane paper surface. The powder was allowed to flow freely unto the paper surface. The height of the cone, $\mathrm{H}$ formed after complete flow and the radius of the cone, $\mathrm{R}$ were measured and used to calculate the angle of repose using the following equation:

\section{Angle of $\operatorname{repose} \theta=\tan ^{-1(h / r)}$}

Where; $\theta=$ Angle of Repose, $\mathrm{h}=$ Weight of powder heap, $\mathrm{r}=$ Radius of powder heap

\section{Bulk and tapped densities}

Polysaccharide (TSP) was accurately weighed (10 gm) into a $100 \mathrm{ml}$ measuring cylinder and without disturbing the cylinder the volume of powder was read to give the bulk volume. The measuring cylinder was then clamped to the USP I tapper of a USP tap density tester (Electro lab, model ETD-1020). The volume of the powder was read after every 25 taps up to a total of 275 taps when volume of powder was constant. This represents the tapped volume of the powder. The bulk density and tapped density was calculated using the following equations.

Bulk Density $=$ (weight of the sample $) /($ Bulk volume $)$

Tapped density $=($ Weight of the sample $) /($ Tapped volume $)$

\section{Compressibility index}

The compressibility index was calculated as follows

$$
\text { Compressibility }(\mathrm{C} \%)=\left(\begin{array}{c}
\text { Tapped Density-Bulk density }) /(\text { Tapped } \\
\text { density })
\end{array}\right.
$$

\section{Hausner ratio}

Hausner ratio is a measure of flow ability of the TSP polysaccharide and is calculated using the following equation. A low Hausner ratio means that the polysaccharide powder has a high follow ability. Hausner ratio above 1.25 indicates poor flow.

Hausner ratio $(\mathrm{H})=($ Tapped density $) /($ Bulk density $)$

\section{Solubility studies}

The polysaccharides obtain from Tamarindus indica was evaluated for solubility in water, acetone, methanol and ether as per Indian Pharmacopoeia specification [6].

\section{Determination of melting point}

Melting point was determined by a capillary tube in melting point apparatus.

\section{Loss on drying}

$500 \mathrm{mg}$ of polysaccharide (TSP) was weighed and placed in a clean and neat china dish. It was kept in hot air oven at $105^{\circ} \mathrm{C}$ until a constant weight was obtained. The china dish was removed from the oven and again the weight of the polysaccharide powder was determined. The moisture content was then determined as the ratio of weight of moisture loss to weight of sample expressed as a percentage [7].

\section{pH OF 1\% solution}

This was done by shaking a $1 \% \mathrm{w} / \mathrm{v}$ dispersion of the sample in water for $5 \mathrm{~min}$ and the $\mathrm{pH}$ determined using adigital $\mathrm{pH}$ meter. The data present here is for triplicate determination [8].

\section{Moisture content}

The moisture content of the powder was carried out by thermos gravimetric method using IR moisture balance [7].

\section{Viscosity of $1 \%$ solution}

The viscosity of $1 \%$ solution was determined by Brook field viscometer (LVDV-E) (Brookfield Engineering Labs, Stoughton-USA) using Spindle 62 at 0, 20, 40 and $60 \mathrm{rpm}$.

\section{Determination of swelling index}

This was done by taking $1.0 \mathrm{~g}$ quantity of in a $15 \mathrm{ml}$ plastic centrifuge tubes and the volume occupied was noted. Ten millilitres of distilled water were added to it and the content was mixed on a vortex mixer (Lab line Equipment, India) for $2 \mathrm{~min}$. The mixture was allowed to stand for $10 \mathrm{~min}$ and immediately centrifuged at 1000 rpm on a bench centrifuge (Remi, India). The supernatant was carefully decanted and the volume of sediment was measured. The swelling index was computed using the following equation.

$$
\mathrm{S}=(\mathrm{V} 2-\mathrm{V} 1) / \mathrm{V} 1 \times 100
$$

Where $\mathrm{S}$ is the \% swelling capacity, V2 is the volume of the hydrated or swollen material and $\mathrm{V} 1$ is the volume of the material prior to hydration. The experiment was repeated by using $0.1 \mathrm{~N} \mathrm{HCL}$ and Phosphate buffer 7.4 in water [7].

\section{Determination of ash value}

$2 \mathrm{~g}$ of polysaccharide (TSP) was weighed accurately in a previously ignited and tarred silica crucible. The material was then ignited by gradually increasing the heat to $500-600{ }^{\circ} \mathrm{C}$ until it appeared white indicating absence of carbon. It is then cooled in a desiccator and total ash in mg per gm of air dried material is calculated. To the crucible containing total ash, $25 \mathrm{ml}$ of 2M HCL was added and boiled gently for $5 \mathrm{~min}$, and then about $5 \mathrm{ml}$ of hot water was added and transferred into crucible. The insoluble matter was collected on an ash less filter paper. This was then washed with hot water until filtrate is neutral and the filter paper along with the insoluble matter was transferred into crucible and ignited to constant weight. The residue was then allowed to cool and then weighed. The percentage of acid insoluble ash was calculated from the weight of the sample taken [9].

\section{Microbial content determination}

Total microbial content was determined by Streak plate (surface plating) method using agar plates [8].

\section{Differential scanning calorimetry}

A differential scanning calorimeter (JADE DSC, Perkin Elmer, and USA) was used to study the thermal properties of the polysaccharide obtained from Tamarindus indica. The polysaccharide was scanned in the temperature range of $50-2200 \mathrm{C}$ under an atmosphere of nitrogen. The heating rate was $200 \mathrm{C} / \mathrm{min}$, followed by a cooling cycle back to $300 \mathrm{C}$ at the same rate [5]. 


\section{Fourier transform-infra red}

The Fourier transform-infra red (FT-IR) spectrum of the sample was recorded in an IR spectrometer (Bruker Alpha FTIR). Triplicate measurements were made, and the spectrum with the clearest identifiable peaks was chosen [5].

\section{RESULTS AND DISCUSSION}

Polysaccharides from Tamarindus indica were purified using water and precipitated with acetone. The percentage yield of the polysaccharide obtained from the TBG was found to be $16.85 \%$.

\section{Charecterization result of polymer}

The purity of polysaccharide was determined by undergoing phytochemical tests such as test for alkaloids, proteins, fats and oils and amino acid whose outcome found to be absent. The purity was confirmed as only carbohydrate was found to be present.

The polysaccharide was characterized by various organoleptic properties such as colour, odour, taste, touch and texture as shown in table 4.1 .

The solubility behaviour of the polysaccharide was carried out which shows that the polysaccharide is soluble in warm water, sparingly soluble in cold water, whereas insoluble in methanol, acetoneand ether.

Swelling index of the Tamarind Seed Polysaccharides (TSP) was found to be high. The ability of swelling of anypolysaccharide is based on its water retention capacity. The $\mathrm{pH}$ of the $1 \% \mathrm{w} / \mathrm{v}$ Tamarind Seed Polysaccharides (TSP) was found to be 6.9. The melting point of polysaccharides was found to be $250{ }^{\circ} \mathrm{C}-260{ }^{\circ} \mathrm{C}$ Moisture content was found to be $8.10 \%$ which results good stability for pharmaceutical dosage forms.

The ash values are measured as high values of ash indicates low level of purity and adulteration of sand and other earthy matter such as carbonates. Here the total ash values for polysaccharide was found to be 1.6050 and the acid insoluble ash value was found to be 0.0996 which indicates high level of purity as the values were found to be very low. The microbial test for the polysaccharide was performed and the count was found to be within limit thus microbial contamination is not a risk factor for the product degradation. The properties such as bulk density, tapped density, compressibility index, hausner's ratio and angle of repose are referred to as properties of the powder to adhere together for better compressibility in a pharmaceutical formulation. Compressibility index (CI) values up to $15 \%$ usually result in good to excellent flow properties and value above $25 \%$ are often sources of poor tableting qualities. The values are found to be within limit and are believed to serve for good flow properties and compressibility. The angle of repose was found to be 29.45 which indicates good flow.

Viscosity of $1 \%$ solution of Tamarind Seed Polysaccharides (TSP) was found to be $1250,620,420$ and 90 Centipoise (cP) at 0,20,40,60 rpm respectively (fig. 1).

Differential scanning calorimetry (DSC) measures the heat loss or gain, resulting from physical or chemical changes within a sample as a function of temperature. A sharp symmetric melting endotherm can indicate relative purity, whereas broad asymmetriccurve suggests impurities or more than one thermal process. The endothermic peak usually indicates the loss of water present in the compound (fig. 2).

FTIR spectroscopy is a useful tool in identification as well as purity of a compound. The principal absorption peaks of Tamarind seed polysaccharide were found to be $1603.47 \mathrm{~cm}^{-1}, 1521.92 \mathrm{~cm}^{-1}$, $1418.90 \mathrm{~cm}^{-1}$ and $1019.14 \mathrm{~cm}^{-1}$ (fig. 3).

\section{Definition of acute toxicity}

Acute toxicity refers to those adverse effects occurring following oral or dermal administration of a single dose of a substance, or multiple doses given within $24 \mathrm{~h}$, or an inhalation exposure of $4 \mathrm{~h}$ [10].

\section{Need of acute toxicity study}

Traditional use of herbal drugs may broadly be divided into three categories as follows:-
-Those are well known and have been widely used for many years.

-Those are not well known in the country but for which international experience is available.

-That represents a new compound hitherto not evaluated as to its safety and efficacy.

The first category mainly consists of foodstuff product (s), which has been in use for a long time as traditional herbal remedies, and the requirements are limited. In general, it these foodstuff products are generally safe for human and animal consumption and establishment of safety of these products is not so important. For the second category, views concerning the type of documents required to be presented may differ from country to country. So it is necessary that varieties of requirements will be elaborated for these products covering anything from reference in scientific literature confirming that the product is safe. To satisfy the demands for limited or shortened toxicological testing of these products, an investigation must be carried out on toxicity profile. The third group, where the authority is faced with a product not previously screened for its toxicological properties, toxicity studies of those product must have to be undertaken.

Tamarind seed polysaccharides has been used for centuries in the Indian traditional system of medicine. The dried fruit and other parts are being in use for medicinal purposes since. According to the traditional use of herbal drug classification the acute toxicity study of the Tamarind seed polysaccharides is not that important as this plant is already being used in tradition. In some of the research it has been already established that Tamarind seed polysaccharides obtained from Tamarindus indica have no acute toxicity effect [11].

\section{CONCLUSION}

The research work was carried out successfully. The polysaccharides were isolated, extracted and characterized. The characterization was carried out for different physiochemical properties and powder properties. Other properties like $\mathrm{pH}$, solubility, flow property, bulk density etc. were found to be in the desired range. Analytical tests like Differential scanning calorimetry and Fourier Transform Infrared Radiation were carried out and the results showed good property of the polysaccharide which can be further used as pharmaceutical excipients.

Table 1: Organoleptic properties of polysaccharides

\begin{tabular}{ll}
\hline Organoleptic properties & \\
\hline Colour & Brown \\
Odour & Odourless \\
Taste & Tasteless \\
Shape & Irregular \\
Touch and Texture & Hard and Rough \\
\hline
\end{tabular}

Table 2: Polysaccharides parameters

\begin{tabular}{ll}
\hline Parameters & Results \\
\hline Swelling index (\%v/v) water & 196 \\
0.1N HCL & 220 \\
Phosphate buffer 6.8 & 455 \\
Loss on drying (\%w/w) & 11 \\
Moisture Content (\%w/w) & 8.10 \\
Total ash (\%w/w) & 1.6050 \\
Acid insoluble ash (\%w/w) & 0.0996 \\
Water soluble ash (\%w/w) & 0.8218 \\
pH & 6.9 \\
Angle of repose (Degree) & 29.45 \\
Bulk density (g/cc) & 0.63 \\
Tapped density (g/cc) & 0.83 \\
Compressibility index (\%) & 24.17 \\
Hausner ratio & 1.03 \\
\hline
\end{tabular}




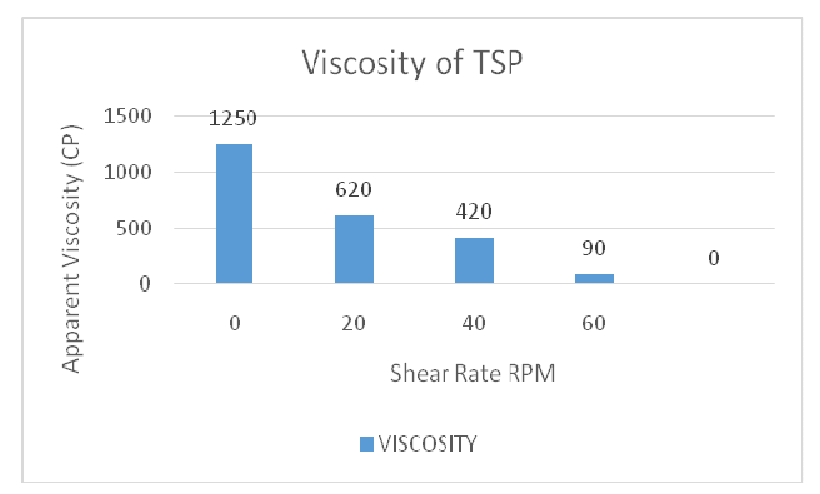

Fig. 1: Viscosity of polysaccharides

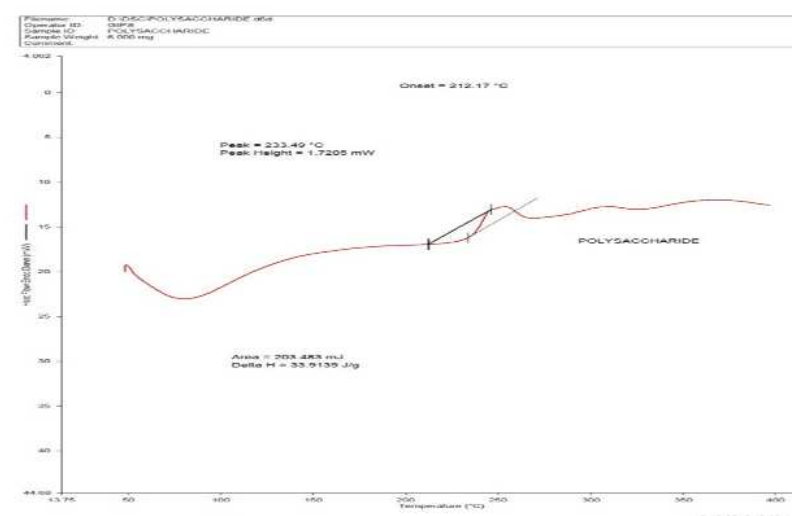

Fig. 2: DSC of polysaccharides

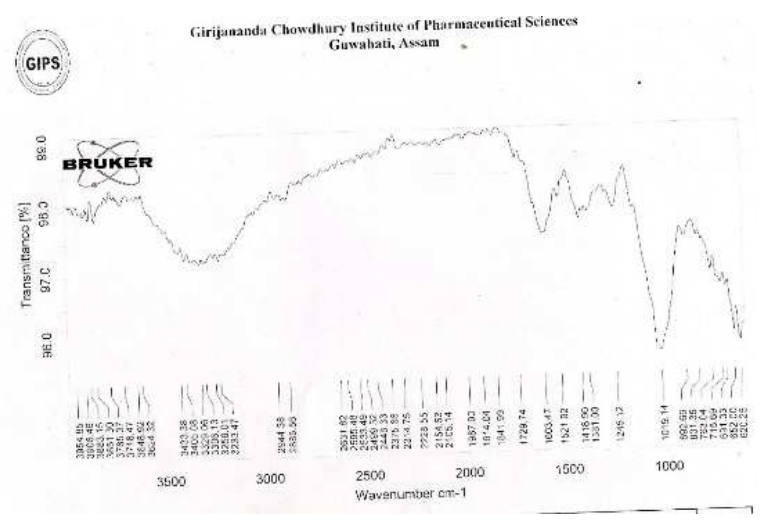

Fig. 3: FTIR of polysaccharides

\section{CONFLICT OF INTERESTS}

Declare none

\section{REFERENCES}

1. Baveja SK, Rao KV, Arora J. Examination of natural gums and mucilages as sustaining materials in tablet dosage forms. Indian J Pharm Sci 1989;5:115-9.

2. Samina Kabir khanzada, W Shaikh, Shahzadi Sofia, TG Kazi, K Usmanghani, Amina Kabir, et al. Chemical constituents of Tamarindus indica medicinal plant in Sindh. Pakistan J Bot 2008;40:2553-9.

3. Yerram Chandramouli, Shaik Firoz, Amaravathi Vikram, B Mahitha, B Rubia Yasmeen, K Hemanthpavankumar. Tamarind seed polysaccharide (TSP)-An adaptable excipient for novel drug delivery systems. Int J Pharm Practice Drug Res 2012;2:57-63.

4. Phani Kumar GK, Gangarao B, Kotha NS, Lova R. Isolation and evaluation of tamarind seed polysaccharide being used as a polymer in pharmaceutical dosage forms. Res J Pharm Biol Chem Sci 2011;2:274.

5. Barath Srinivasan, Anusha Ganta, Deveswaran Rajamanikam, Basavaraj Basappa, Madhavan Varadharajan. Evaluation of tamarind seed polysaccharides as drug release retardant. Int J Pharm Sci Rev Res 2001;9:27-31.

6. Anonymous. The British Pharmacopoeia. British Pharmacopoeia Commission. 200 Her Majesty's stationary office. London. A; 2004. p. 13.

7. Kulkarni G. Development of controlled release spheroids using natural polysaccharide as release modifier. Drug Delivery 2005;12:201-6.

8. Kulkarni D, Ddwivedi DK, Sarin JPS, Singh S. Tamarind seed polyose: a potential polysaccharide for sustained release of verapamil hydrochloride as a model drug. Indian J Pharm Sci 1997;59:1-7.

9. Das B, Dash S, Choudhury RC, Chakraborty J, Deb Roy S. Optimization and characterization of purified polysaccharide from Terminalia Belarica Gum as pharmaceutical excipient. Int J Pharm Res Allied Sci 2014;3:21-9.

10. Rashmi Manchanda, Arora SC, Rajesh Manchanda. Tamarind seed polysaccharide and its modifications versatile pharmaceutical excipients-a review. Int J PharmTech Res 2014;6:412-20.

11. Anonymous. Determination of the GRAS status of the addition of tamarind seed polysaccharide to conventional foods as a stabilizer and thickener. Available from: https://www.fda.gov/ downloads/Food/IngredientsPackagingLabeling/GRAS/Notice Inventory/ucm403104.pdf. [Last accessed on 15 Dec 2016]

\section{How to cite this article}

- Trideep Saikia, Jonab Ali, Biswajit Das. Isolation and charecterization of tamarind seed polysaccharides-a natural release retardant. Int J Curr Pharm Res 2017;9(4):114-117. 